\title{
A FOTOGRAFIA PARTICIPATIVA COMO FERRAMENTA DE EXPRESSÃO E REPRESENTAÇÃO social. Foto-ensaio do Projecto "Olhares em Foco"
}

\author{
Daniel Meirinho ${ }^{1}$ \\ Universidade Nova de Lisboa
}

\begin{abstract}
Este foto-ensaio é fundamentado no projecto de investigação-ação chamado "Olhares em Foco" que se propóe trabalhar a imagem fotográfica como elemento importante de (re)construção e reflexão identitária de jovens provenientes de contextos socioeconómicos vulneráveis, de comunidades formadas por minorias étnicas e sociais. Através da formação em técnicas fotográficas, análise das imagens e debates, procurámos estabelecer reflexões identitárias, a partir de parâmetros de relaçôes sociais estruturadas entre eles (cidadãos), a sociedade, a sua família e comunidade.
\end{abstract}

Palavras-chave: fotografia participativa, photovoice, investigação visual

\section{INTRODUÇÃo}

Nossa investigação privilegia os jovens enquanto criadores, e não somente receptores das imagens que circulam ao seu redor. A base conceitual é fundamentada nas estratégias concebidas pelo procedimento metodológico photovoice ${ }^{2}$. Este conceito foi desenvolvido em 1992 pelas investigadoras Caroline Wang da Universidade de Michigan e Mary Ann Burris da Universidade de Londres. A proposta metodológica parte da utilização da fotografia como ferramenta de base para a acção social e desenvolvimento comunitário. Os participantes são convidados para representar sua comunidade ou ponto de vista, tirando fotografias, discutindoas em conjunto, desenvolvendo narrativas para, juntamente com as imagens produzidas, realizar

1 Daniel Meirinho faz doutoramento em Ciências da Comunicação. Trabalha como investigador do Centro de Media e Jornalismo (CIMJ) da Faculdade de Ciências Sociais e Humanas da Universidade Nova de Lisboa. É colaborador do Laboratório de Antropologia Visual do Centro de Estudos das Migrações e das Relações Interculturais (CEMRI) da Universidade Aberta de Lisboa.

2 A partir das fotografias captadas, foram estimulados debates entre os participantes. Os dados colectados, tanto das imagens fotográficas quanto dos debates, estão a ser ainda analisados e cruzados em estratégias de análise quantitativa e qualitativa entre texto e imagem. 
acções comunitárias. Dentro deste estudo a fotografia foi uma ferramenta de "representação de perspectivas dos que levam uma vida diferente daqueles que tradicionalmente possuem o controlo dos meios de imagem do mundo"(Wang, 2006: 154).

Várias questões guiaram essa investigação tais como: qual o uso que os jovens em situação de exclusão dão aos equipamentos de captação fotográfica? Que olhares eles possuem da sua esfera social e da sua realidade? Como eles observam a representação feita pelos meios de comunicação sobre suas realidades? Eles sentem a necessidade de mostrar realidades diferentes das suas nas imagens? De que forma eles a representam? Quais são os factores que influênciam na escolha de determinados objectos a serem fotografados e nos seus enquadramentos?

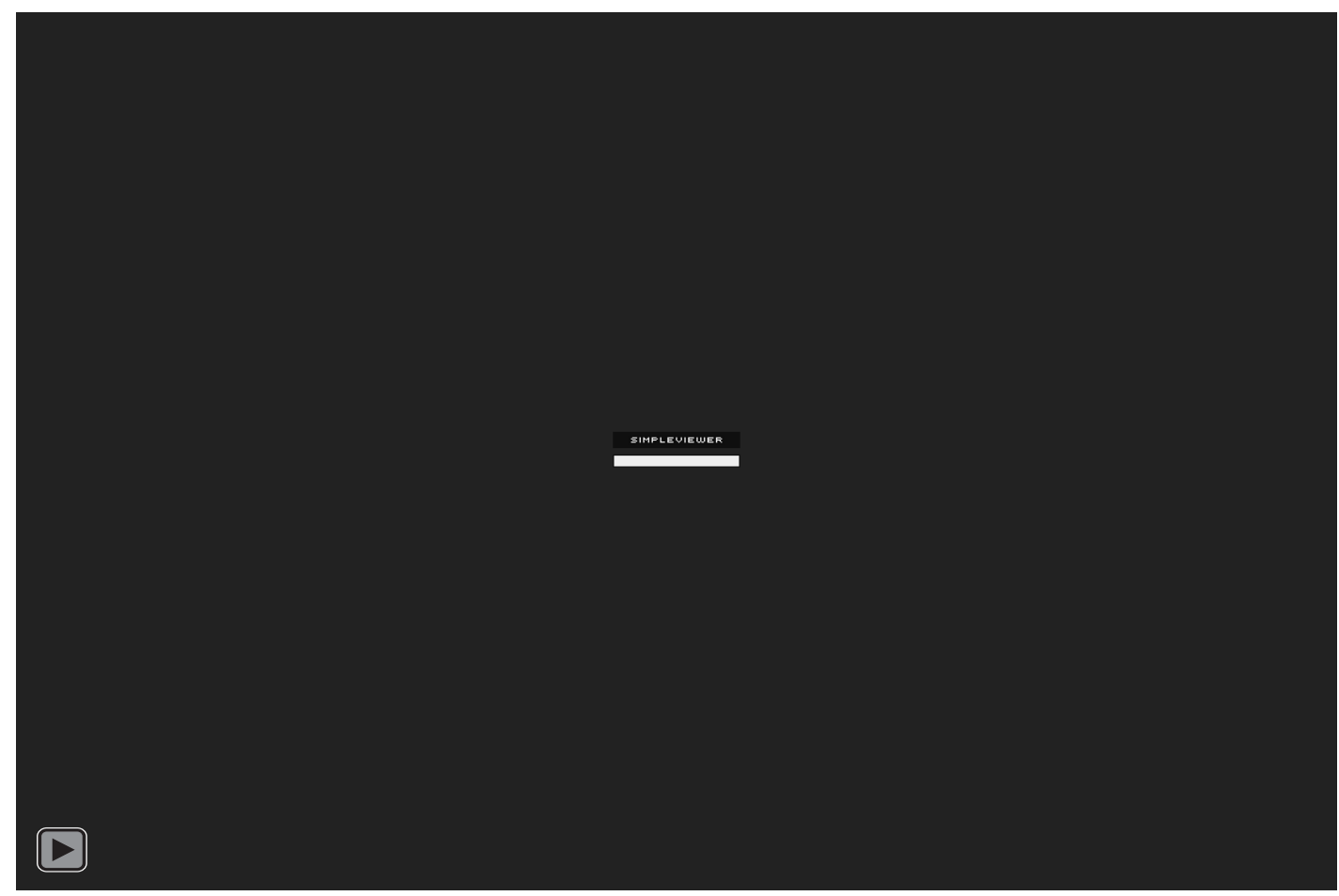

\section{O projecto "Olhares em Foco"}

O projecto "Olhares em Foco" foi dinamizado no Brasil, em parceria com o "Fundo Cristão para Crianças" entre os meses de Março e Maio de 2011. Duas comunidades do Estado brasileiro de Minas Gerais foram escolhidas como acolhedoras da iniciativa. Uma comunidade rural quilombola ${ }^{4}$ chamada Pega, na região do Vale do Jequitinhonha, conhecido pejorativamente como "Vale da Fome" (com cerca de 50 famílias residentes). A outra foi uma

3 O Fundo Cristão para Crianças é uma Organização Não-Governamental. Trabalha no Brasil há 45 anos na elaboração e monitoramento de programas e projectos sociais com crianças, adolescentes, jovens, famílias e comunidades em situação de risco social. Afiliado ao ChildFund International, o FCC beneficia por meio de projectos sociais cerca de 220 mil pessoas, dentre elas 143 mil são crianças, adolescentes e jovens. A rede é composta por 93 organizações que actuam em 862 comunidades urbanas e rurais.

4 Quilombo é um assentamento fundado por pessoas de origem africana descendentes de escravos que fugiram nos tempos da escravatura no Brasil. A Constituição Brasileira de 1988 concedeu a propriedade colectiva das terras aos remanescentes de quilombos que ocuparam desde os tempos coloniais, reconhecendo assim a sua identidade distinta no mesmo nível dos índios. 
área urbana, chamada Favela do Cafezal, que faz parte do Aglomerado da Serra onde residem em torno de 65 mil pessoas, na cidade de Belo Horizonte.

Cada área de intervenção possuía problemáticas e necessidades distintas. No entanto, desfrutavam de uma linha convergente estruturada na marginalização e exclusão como minoria étnica e social. Buscamos, em projectos de intervenção social como "Kids With Cameras", "Shoot Nations", "Olhares do Morro"7 "Olhar Colectivo" e o projecto "Photovoice", elementos de confluência com a nossa investigação.

O projecto teve início na Comunidade Pega, que fica a cerca de $560 \mathrm{~km}$ de Belo Horizonte, no semi-árido mineiro. A vila é isolada e as estradas que ligam a comunidade têm acesso limitado e não são asfaltadas. As casas não possuem saneamento básico, sinal de telefonia móvel e poucas tinham televisão. Participaram 20 jovens com idades entre 12 e 18 anos, de ambos os sexos. Foram realizados 14 encontros, num total de 56 horas e os jovens produziram 3.119 fotografias. Os adolescentes fotografaram entre si, suas famílias e casas e a comunidade, além de fazerem uma saída externa e fotografarem a feira do Sábado que é realizada na pequena cidade de Virgem da Lapa, a $10 \mathrm{~km}$ do Pega. As feiras aos sábados são de extrema importância para os moradores da região pois é onde vendem os seus produtos agrícolas e compram o que não produzem de outros agricultores e pecuaristas.

Na Favela do Cafezal, uma das oito vilas do Aglomerado da Serra, participaram 19 jovens com idades entre 10 e 16 anos. Como toda área urbana com alto índices de pobreza no Brasil, a maior problemática era a violência e o tráfico de drogas organizado. Os jovens produziram 2.638 fotografias em 15 encontros que somaram 48 horas. Os jovens fotografavam mais a comunidade e estavam bem mais familiarizados com o equipamento digital disponibilizado para que eles pudessem fazer as fotografias. Os grupos de amigos foram muito valorizados nas imagens. No entanto, o movimento do tráfico na comunidade nunca foi fotografado pelo respeito que os jovens possuem aos limites e prejuízos que isto poderia lhes causar e a sua família.

O projecto foi dinamizado com câmaras digitais doadas pelo Fundo Cristão para Crianças. Todos levaram as câmaras para suas casas e fotografaram a si próprios, a sua família, amigos e contexto social onde se encontravam inseridos (projectos, escola, comunidade, espaço geográfico, associações, entre outros). Por onde o projecto passava as câmaras ficavam doadas para a instituição comunitária que acolheu o projecto e à exclusiva disposição dos jovens participantes. Todo o material didáctico foi entregue aos jovens e disponibilizado numa rede virtual criada onde eles tinham a possibilidade de aceder, fazer seus perfis, incluir fotos, vídeos, participar de chats e enviar mensagens. Desta forma, foi criada a "Rede Virtual Olhares em Foco" onde os jovens do Vale do Jequitinhonha poderiam interagir com os do Aglomerado da Serra e possivelmente com outros que o projecto poderá ainda contemplar.

No fim de cada projecto foi realizada uma exposição fotográfica com as imagens captadas pelos jovens. Todo o processo foi partilhado com jovens num processo cooperativo entre os investigadores e os participantes da oficina. Para o momento final de exposição dos trabalhos

\footnotetext{
$5 \quad$ Ver em http://www.kids-with-cameras.org

6 Ver em http://po.shootnations.org

7 Ver em http://www.olharesdomorro.org

8 Ver em http://www.olharcoletivo.org

9 Ver em http://www.photovoice.org
} 
dos jovens foi convidada toda a comunidade, pais, líderes comunitários, representantes de associações de intervenção social, escola e entidades públicas locais de apoio e assistência às crianças e ao jovem.

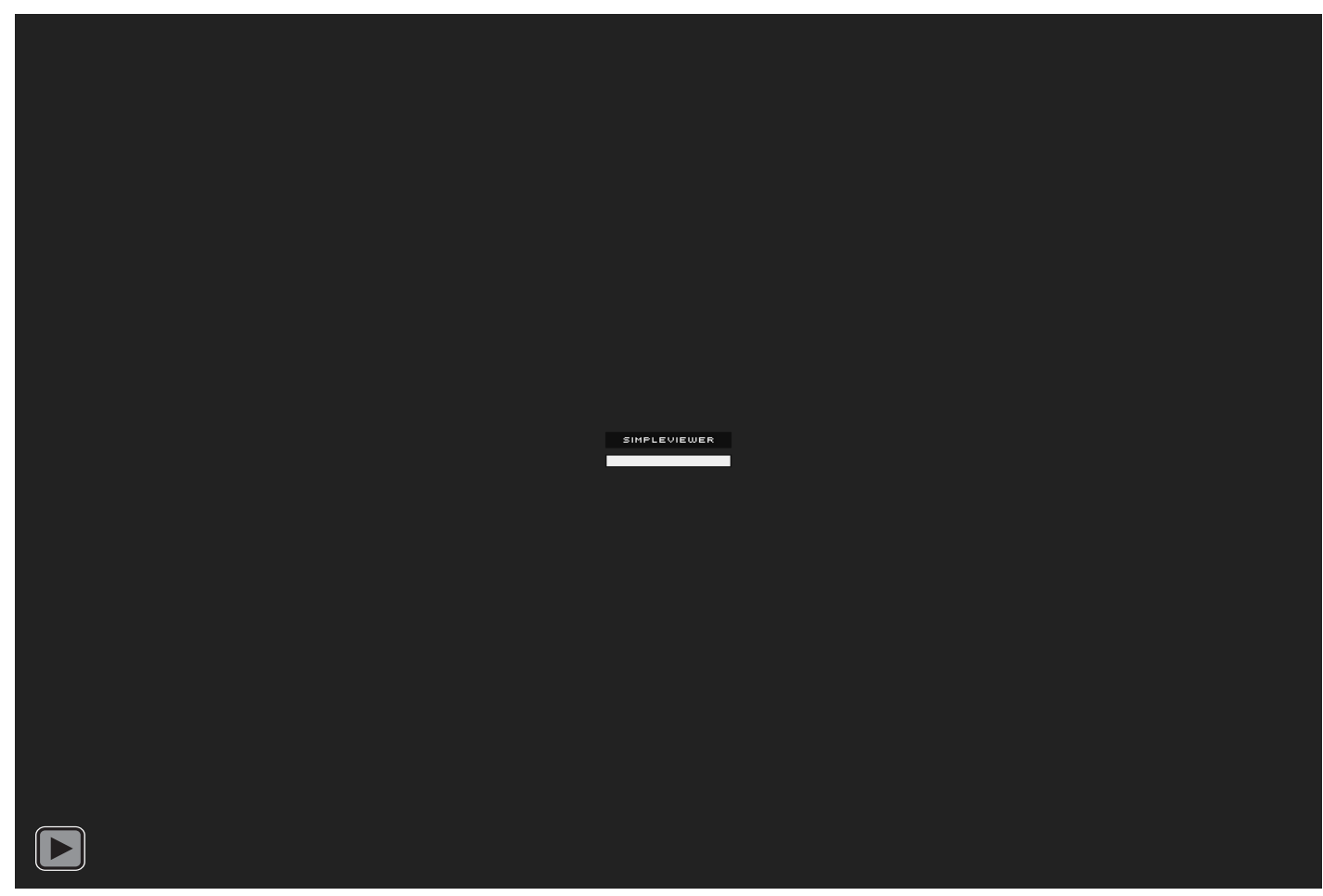

\section{NOTAS CONCLUSivas}

Nos propusemos a uma investigação-acção em que a fotografia foi instrumento de expressão que operou no sentido da reflexão identitária e do resgate da auto-estima de jovens em situação de exclusão social e cultura $1^{10}$. Diversos estudos trabalham a influência que os media exercem nos hábitos desta parcela da sociedade, através da reprodução repetitiva de imagens, ora positivas ora negativas. Desta forma, a educação para os media e a consequente literacia mediática podem constituir um antídoto para o aumento das problemáticas sociais apresentadas por estes jovens (Van Horn, 2002).

O material visual foi, sem sombra de dúvidas, um instrumento para estimular o diálogo e as relações de confiança para que os jovens fossem capazes de partilhar as suas experiências, permitindo assim uma discussão mais aprofundada sobre a sua identidade. As fotografias captaram momentos e eventos significativos em suas vidas e estimularam reflexões importantes no tocante às identidades dos jovens, necessidades e problemáticas das comunidades onde residem..$^{11}$

10 Teorias apoiadas na imagem, Semiótica, Antropologia Visual, Literacia e educação para os media foram utilizadas como fundamento para este estudo. Esta análise ainda está a ser desenvolvida no que pretendemos amarrar uma discursividade comum, que é representada na imagem fotográfica produzida pelos jovens.

11 Mais informações sobre o projecto "Olhares em Foco": www.wix/olharesemfoco/projecto. 


\section{REFERÊNCIAS}

Allen, D. 2002. "Research Involving Vulnerable Young People: A Discussion of Ethical and Methodological Concerns”, Drugs: Education, Prevention and Policy 9(3): 275-83.

Caetano, A. 2008. "Sociologia e fotografia. Retrato sociológico do estado da relação em Portugal”. CIES-ISCTE E-Working Paper no42/2008. Retirado em 27 de Junho de 2010 (http://repositorio.iscte.pt/bitstream/10071/714/1/CIESP42_Caetano_.pdf).

Christensen, P e A. James. 2000. Research with Children. London: Routledge.

Corsaro, W. 2003. We're friends, right? Iinside kids' cultures. Washington, DC: Joseph Henry.

Harper, D. 1998. “An Argument for Visual Sociology”, em J. Prosser (ed.) Imagebased

Research. London: Falmer Press.

Lieberman AF, Van Horn P. 1998. "Attachment, trauma, and domestic violence. Implications for child custody". Child and Adolescent Psychiatric Clinics of North America (7):423-443.

Walker, R. 1993. "Finding a Silent Voice for the Researcher: Using Photographs in Evaluation and Research", em M. Schratz (ed.) Qualitative Voices in Educational Research. London: Falmer Press.

Wang, C. C. 2006. "Youth participation in photovoice as a strategy for community change". Journal of Community Practice (14):147-161.

Woodward, S. 2008. "Digital Photography and Research Relationships: Capturing the Fashion Moment”, Sociology 42: 857-72.

\section{PARTICIPATORY PHOTOGRAPHY AS A TOOL FOR SOCIAL REPRESENTATION AND articulation. Photo-essay from the project "Olhares em Foco"}

\footnotetext{
The present photo-essay is based on an action-research project called Olhares em Foco ("Looks brought into focus"). The project employs photographic images, acknowledging their importance within processes of identity (re)construction of young people from social or ethnic minorities. By training photographic techniques, picture analyses and debate, it is attempted to stimulate a deeper reflection on identity and social relations between society at large, family, community and the young people themselves.
}

Keywords: participatory photography, photovoice, visual research. 